\title{
Malignant melanoma on a thermal burn scar
}

\author{
Han Byul Lee, \\ So Eun Han, \\ Lan Sook Chang, \\ Soo Hyang Lee \\ Department of Plastic and \\ Reconstructive Surgery, Inje University \\ Ilsan Paik Hospital, Inje University \\ College of Medicine, Goyang, Korea
}

\begin{abstract}
Chronic burn scars often cause various skin malignancies at rates of up to $2 \%$. These lesions are usually squamous cell carcinomas, but rarely, malignant melanoma is reported. We report a 67-year-old male with a malignant melanoma on a burn scar with regional metastasis. This patient presented an ulcerative lesion only in 2 weeks. After histopathological diagnosis, we performed only palliative surgery on patient's demand, and followed up the subsequent deterioration course. Our case reemphasizes the need for rapid diagnosis and treatment when suspect lesions are present on chronic burn scar. Also, physician should be in mind and inform the patient about malignant melanoma and its aggressive course.
\end{abstract}

Keywords: Burn / Melanoma / Skin neoplasms

\section{INTRODUCTION}

Burn scar, especially if the skin is healed by secondary intention, is a risk factor for the development of various skin cancers. The most common skin cancer on a thermal injury scar is squamous cell carcinoma, followed by basal cell carcinoma [13]. Cases of atypical malignant tumors, such as malignant melanoma, have occasionally been reported, but its incidence is extremely low. Here, we describe a 67-year-old male with suddenonset, rapidly growing, metastatic malignant melanoma on a healed burn area.

\section{CASE REPORT}

A 67-year-old male patient presented with an ulcerated skin lesion that had appeared on his right cheek about 2 weeks earlier. Approximately 30 years prior to presentation, the right side of his face had been burned deeply by boiling water. The wound was left to heal by secondary intention. The initial examination

\footnotetext{
Correspondence: Soo Hyang Lee

Department of Plastic and Reconstructive Surgery, Inje University Ilsan Paik Hospital, Inje University College of Medicine, 170 Juhwa-ro, Ilsanseo-gu,

Goyang 10380, Korea

E-mail: shyanglee@naver.com
}

Received August 24, 2018 / Revised September 15, 2018 / Accepted October 2, 2018 showed a $12 \times 8-\mathrm{cm}$ hypopigmented, contracted scar with a central $2 \times 3$-cm ulcer (Fig. 1). Also, although the patient was unaware of it, there was a tiny nodule on the right submandibular area that was palpable. This skin lesion was diagnosed histopathologically as a nodular type of malignant melanoma. Melanocytic tumor cells were found from the basal layer to deep dermis and atypical mitotic figures are noted (Fig. 2). With human melanoma black 45 immunohistochemistry, tumor cells are strongly stained (Fig. 3). Tumor cell invasion was confirmed, based on a Breslow's depth of $9 \mathrm{~mm}$ and Clark level IV staging (reticular dermis). By positron emission tomographycomputed tomography, we detected abnormal uptake of fluorodeoxyglucose on the right cheek, intraparotid area, and submandibular area (Fig. 4).

We planned wide excision of primary skin lesion with sentinel lymph node biopsy, cervical lymphadenectomy, superficial parotidectomy and postoperative interferon- $\alpha$ treatment. However, he had been diagnosed with a cerebral infraction 15 years ago, and total occlusion of all cerebral major vessels was observed on the preoperative brain magnetic resonance imaging. The anesthesiology and neurology departments had warned of the possibility of intraoperative stroke, and his family refused a curative operation, opting for palliative surgery. Palliative excision with a $2-\mathrm{cm}$ margin and a split-thickness skin graft were 


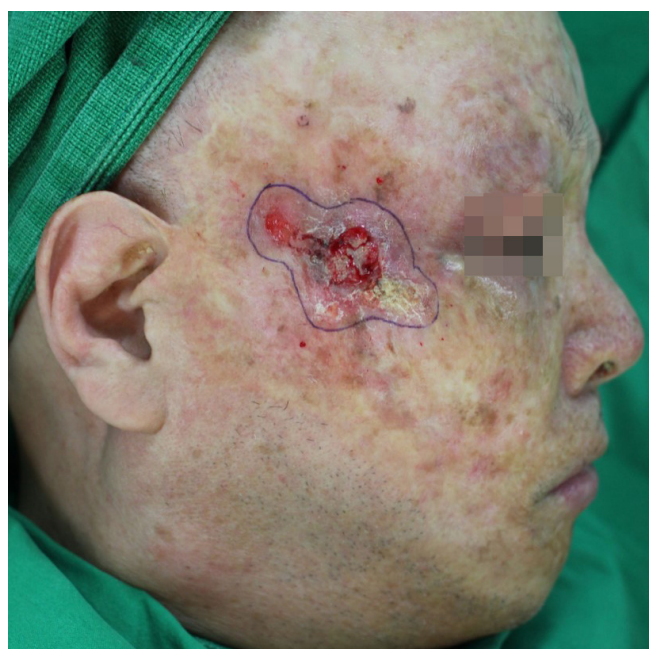

Fig. 1. An approximately $12 \times 8-\mathrm{cm}$ hypopigmented, contracted scar with a central $2 \times 3-\mathrm{cm}$ ulcer.

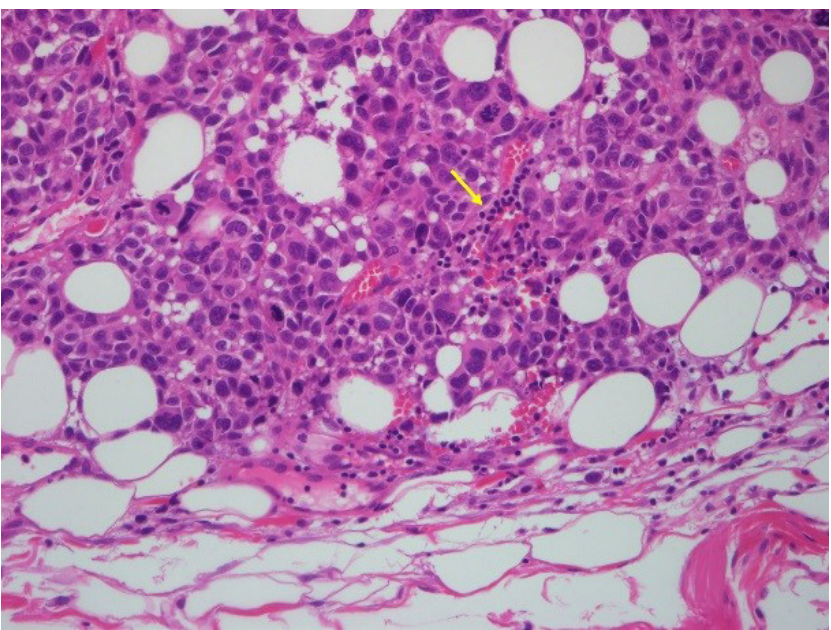

Fig. 2. Melanocytic tumor cells and atypical mitotic figures (yellow arrow) are noted (H\&E, $\times 200)$.

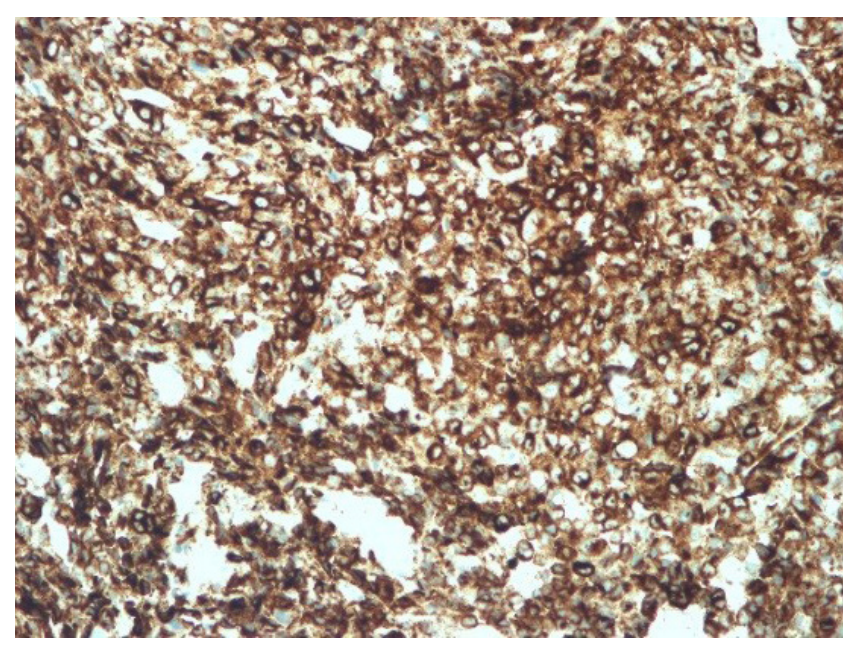

Fig. 3. Tumor cells are strongly stained with human melanoma black 45 immunohistochemistry $(\times 200)$.
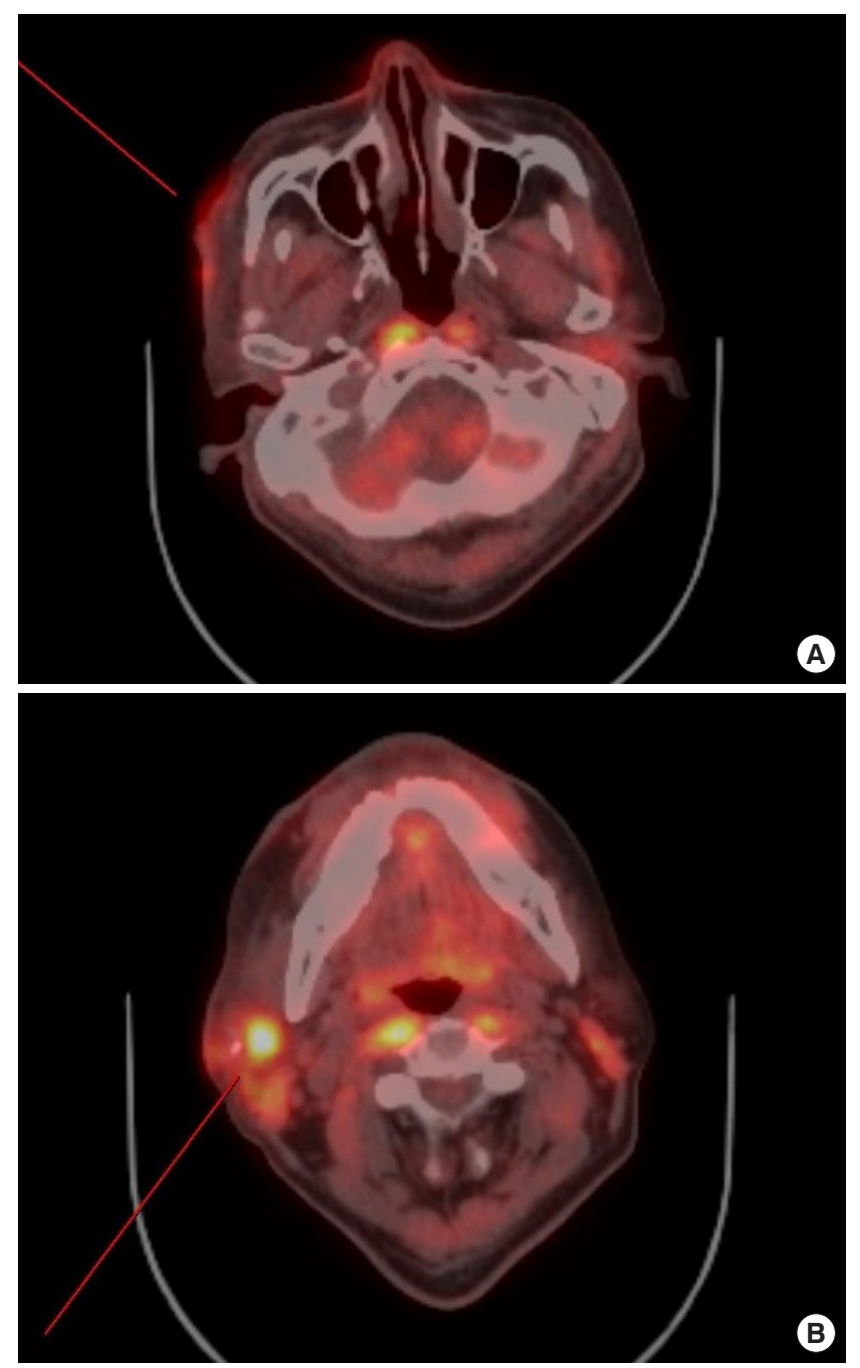

Fig. 4. Fluorodeoxyglucose uptakes were seen at positron emission tomography-computed tomography in right cheek (A) and right submandibular area (B).

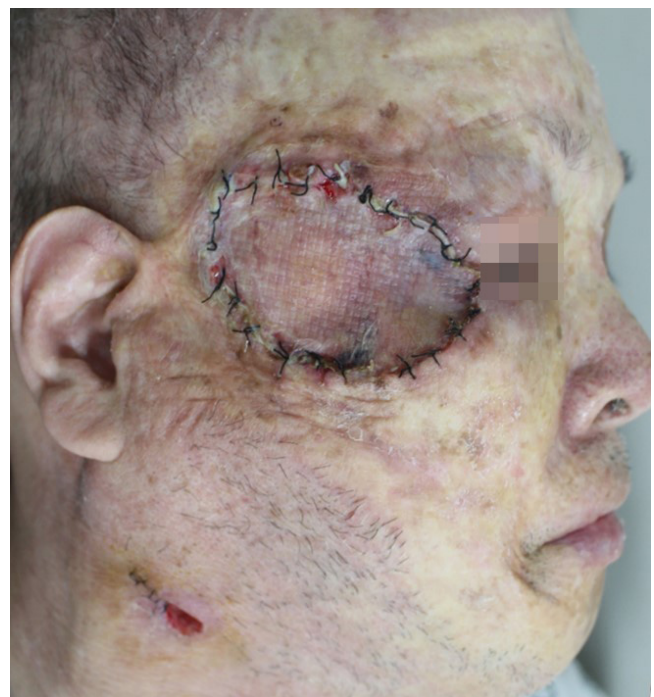

Fig. 5. Normal graft take 1 week after surgery. 


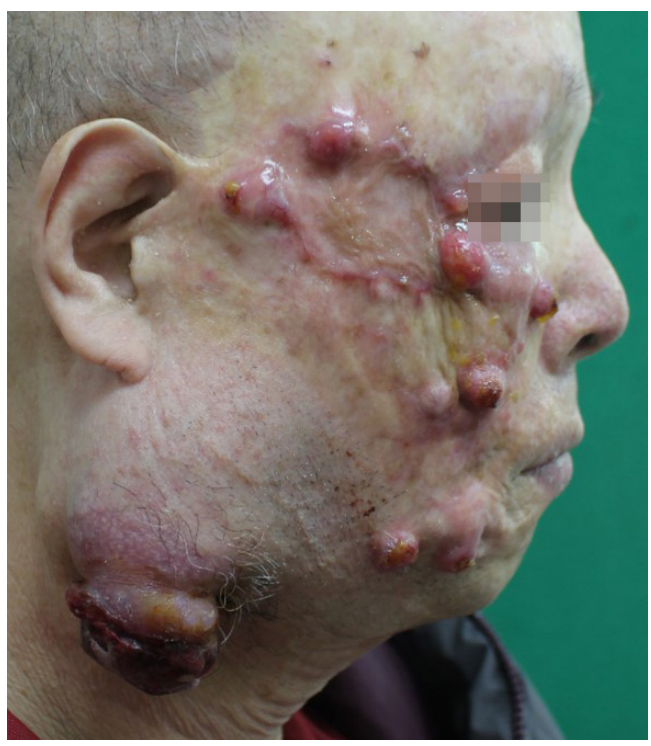

Fig. 6. Multiple nodular lesions on the entire right side of the face and submandibular lymph nodes at 2 months after diagnosis.

performed (Fig. 5). On permanent pathological biopsy, clear resection margin was confirmed. The patient refused any adjuvant therapy, and 2 months later, tumor ingrowth to the entire facial region was observed (Figs. 6, 7).

\section{DISCUSSION}

It is estimated that $2 \%$ of burn scars undergo malignant change [1], and the mean time from injury to a diagnosis of cancer ranges from 23 to 27 years $[4,5]$. There are numerous hypotheses to explain the risk factors and mechanisms of burn scar carcinomas. The healed burn scar, especially if the skin is healed by secondary intention, no longer has the normal components of skin, such as the dermis, vessels, and adnexa. This condition is more susceptible with chronic traumas and thermal injuries. Also, cytotoxins from autolysis and heterolysis in chronic scars might induce this malignant change $[1,2,6]$.

Squamous cell carcinoma is the most common malignancy in burn scars [1-3]. Occasionally, other types of cancer, such as basal cell carcinoma, malignant fibrous histocytoma, sarcoma, and melanoma, are reported $[7,8]$. The first case of malignant melanoma that developed on a burn scar was described in 1965 by Giblin et al. [9]. Since then, few malignant melanomas on burn scars have been reported.

Kowal-Vern and Criswell [6] analyzed 23 cases of malignant melanoma on burn scars. They reported an average duration of ulcerative lesion before initial diagnosis of 7 months. In our case, initial diagnosis and surgical treatment on primary lesion were performed within 1 month that was relatively early period.

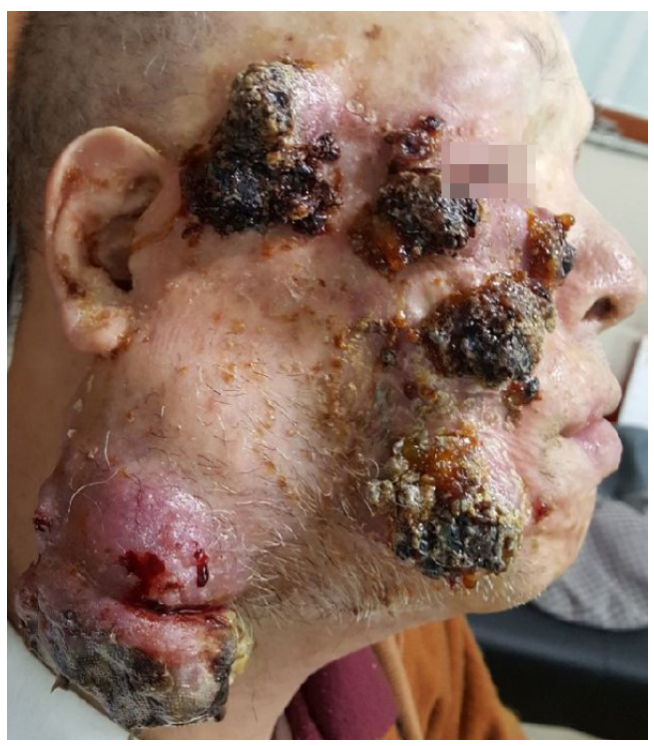

Fig. 7. Rapidly growing nodular, ulcerative lesions with massive discharge 2 weeks after the last visit.

Nevertheless, the patient did not want radial treatment involving adjuvant therapy, so only after 2 months he showed a rapid deterioration of regional metastasis.

Based on our experience, chronic burn scars should be monitored carefully with regard to the possibility of malignant melanoma. Even if the latency period from previous burns is long or if the onset of acute lesion is rapid, suspicious lesions must be examined by tissue biopsy, and treatment should be started as soon as possible. The rate of progression of the disease must also be explained to the patient.

\section{NOTES}

\section{Conflict of interest}

No potential conflict of interest relevant to this article was reported.

\section{Ethical approval}

The study was performed in accordance with the principles of the Declaration of Helsinki. Written informed consent was obtained.

\section{Patient consent}

The patient provided written informed consent for the publication and the use of his images.

\section{ORCID}

Han Byul Lee https://orcid.org/0000-0002-1147-7678

So Eun Han 
Lan Sook Chang https://orcid.org/0000-0003-4725-772X

Soo Hyang Lee https://orcid.org/0000-0002-1679-5624

\section{REFERENCES}

1. Treves N, Pack GT. The development of cancer in burn scars: an analysis and report of thirty-four cases. Surg Gynecol Obstet 1930;51:749-82.

2. Edwards MJ, Hirsch RM, Broadwater JR, Netscher DT, Ames FC. Squamous cell carcinoma arising in previously burned or irradiated skin. Arch Surg 1989;124:115-7.

3. Orlet HK, Still J, Law E, Gertler C. Malignant melanoma in a burn scar. Ann Plast Surg 2001;46:59-61.
4. Stromberg BV, Keiter JE, Wray RC, Weeks PM. Scar carcinoma: prognosis and treatment. South Med J 1977;70:821-2.

5. Fleming MD, Hunt JL, Purdue GF, Sandstad J. Marjolin's ulcer: a review and reevaluation of a difficult problem. J Burn Care Rehabil 1990;11:460-9.

6. Kowal-Vern A, Criswell BK. Burn scar neoplasms: a literature review and statistical analysis. Burns 2005;31:403-13.

7. Stromberg BV, Klingman R, Schluter WW. Basal cell burn carcinoma. Ann Plast Surg 1990;24:186-8.

8. Gargan TJ, Mitchell L, Plaus W. Burn scar sarcoma. Ann Plast Surg 1988;20:477-80.

9. Giblin T, Pickrell K, Pitts W, Armstrong D. Malignant degeneration in burn scars: Marjolin's ulcer. Ann Surg 1965;162:291-7. 